ORIGINAL ARTICLE

\title{
Lactate threshold responses to a season of professional British youth soccer
}

\author{
K McMillan, J Helgerud, S J Grant, J Newell, J Wilson, R Macdonald, J Hoff
}

Br J Sports Med 2005;39:432-436. doi: 10.1136/bjsm.2004.012260

See end of article for authors' affiliations

.....................

Correspondence to: Kenny McMillan, Glasgow Celtic FC, Medical Department, 95 Kerrydale Street, Glasgow G40 3RE, UK; kennymcmillan@ hotmail.com

Accepted 22 August 2004

\begin{abstract}
Objective: To examine the changes in aerobic endurance performance of professional youth soccer players throughout the soccer season.

Methods: Nine youth soccer players were tested at six different time points throughout the soccer season by sub-maximal blood lactate assessment, using an incremental treadmill protocol. Whole blood lactate concentration and heart frequency $(\mathrm{Hf})$ were determined at each exercise stage. Running velocities at the first lactate inflection point $\left(v-\mathrm{T}_{\text {lac }}\right)$ and at a blood lactate concentration of $4 \mathrm{mmol} \mathrm{I}^{-1}(v-4 \mathrm{mM})$ were determined.

Results: Running velocity at the two lactate thresholds increased from the start of pre-season training to the early weeks of the competitive season, from $11.67(0.29)$ to $12.96(0.28) \mathrm{km} \mathrm{h}^{-1}$ for $v$ - $\mathrm{T}_{\text {lac, }}$ and from $13.62(0.25)$ to $14.67(0.24) \mathrm{km} \mathrm{h}^{-1}$ for $v-4 \mathrm{mM}(\mathrm{p}<0.001)$. However, $v$ - $\mathrm{T}_{\text {lac }}$ and $v-4 \mathrm{mM}$ when expressed relative to maximum heart frequency $\left(\mathrm{Hf}_{\text {max }}\right)$ remained unchanged. The $\mathrm{Hf}$ to blood lactate concentration relationship was unchanged after the pre-season training period. The two expressions of lactate threshold did not reveal differences between each other.

Conclusion: Running velocity at $v-\mathrm{T}_{\text {lac }}$ and $v-4 \mathrm{mM}$ increased significantly over the pre-season period, but $v$ - $\mathrm{T}_{\text {lac }}$ and $\mathrm{v}-4 \mathrm{mM}$ were unchanged when expressed relative to $\mathrm{Hf}_{\text {max }}$. This finding may indicate that increased endurance performance may be mainly attributable to alterations in $\mathrm{Vo}_{2 \text { max }}$. Although lactate assessment of soccer players is useful for determining endurance training adaptations in soccer players, additional assessment of the other two determinants of endurance performance $\left(\mathrm{Vo}_{2 \max }\right.$ and running economy) may provide more useful information for determining physiological adaptations resulting from soccer training and training interventions.
\end{abstract}

A number of fitness components have been identified as being important for the soccer player, including aerobic fitness, anaerobic fitness components (such as jumping ability and acceleration), strength, and flexibility. ${ }^{1}$ The importance of aerobic fitness in professional soccer is highlighted by the facts that elite players cover $10-12 \mathrm{~km}$ during a competitive match at an average intensity of around $75 \%$ of their maximal oxygen uptake $\left(\mathrm{Vo}_{2 \max }\right)$ and that the aerobic system contributes approximately $90 \%$ of the total energy cost of match play. ${ }^{23}$ High aerobic endurance performance has the potential to optimise soccer performance by enhancing recovery from high intensity intermittent bouts during match play, thereby contributing to the ability to sustain a high work rate throughout a full competitive match. ${ }^{3}$ Thus, it is of importance to monitor the aerobic endurance performance of professional soccer players periodically throughout the soccer season.

Sub-maximal blood lactate assessment is a useful tool for detecting changes in endurance fitness, ${ }^{5}$ with lactate threshold determination possibly being a more sensitive indicator of aerobic endurance performance than $\mathrm{Vo}_{2 \text { max }} \cdot{ }^{6-8} \mathrm{~A}$ higher lactate threshold theoretically means that a player could maintain a higher average intensity during a soccer match without accumulation of lactate. ${ }^{39}$ Sub-maximal blood lactate assessment has been previously utilised by researchers when assessing the aerobic fitness of soccer players. Blood lactate assessment has been used to monitor aerobic fitness changes across a pre-season and in-season intermission period with professional Danish players, ${ }^{2}$ and throughout a soccer season with professional English players, ${ }^{10}{ }^{11}$ across two soccer seasons with an elite Scottish soccer team, ${ }^{12}$ and over a 3 year period with international female Danish players. ${ }^{13}$

The aims of this study were: (a) to examine the changes in sub-maximal blood lactate measurement of professional Scottish youth soccer players throughout the soccer season; (b) to test whether two different established methods for determining lactate thresholds correlate; and (c) to discuss the possible limitations of lactate threshold measurements in terms of discrimination between the factors contributing to aerobic endurance performance.

\section{METHODS \\ Subjects}

Thirty seven male youth professional soccer players with a mean (standard deviation, SD) age of $18.3(0.3)$ years participated in this study. The players were required to sign a consent form and medical questionnaire after being informed of the procedures and risks involved before each assessment. The study was approved by the local ethics committee.

The study involved the players being assessed by submaximal blood lactate measurement on a treadmill at six time points throughout a soccer season: July (beginning of pre-season training); October; December; January; April; and June (end of soccer season). Data collected from players who missed one or more testing time points were excluded from the analysis. Nine players were available at all six testing time points and their physical characteristics are presented in table 1.

Abbreviations: $\mathrm{FBLC}$, fixed blood lactate concentration; $\mathrm{HF}$, heart frequency; SD, standard deviation 
Table 1 Physical characteristics of players $(n=9)$

\begin{tabular}{lccc}
\hline Age (years) & Height $(\mathrm{cm})$ & Mass $(\mathrm{kg})$ & Hf $_{\max }$ (beats $\left.\mathbf{m i n}^{-1}\right)$ \\
\hline $17.8(0.2)$ & $177.7(1.1)$ & $71.3(3.2)$ & $204.9(1.6)$ \\
\hline \multicolumn{4}{l}{ Values are mean (SD). Hf, heart frequency. }
\end{tabular}

\section{Testing}

Each player performed a 5 min warm up on a Woodway ERGO ES2 treadmill (Cranlea, Birmingham, UK) at a velocity that elicited a heart frequency (Hf) of approximately $60 \%$ of estimated maximum $\left(\mathrm{Hf}_{\max }\right)$. Thereafter, the subjects carried out stretching exercises of their own choice for $5 \mathrm{~min}$. The test protocol consisted of individual 4 min exercise stages, with a $0.5 \mathrm{~km} \mathrm{~h}^{-1}$ increase in treadmill velocity until test termination. Each assessment started at a treadmill velocity that elicited a $\mathrm{Hf}$ of approximately $60 \% \mathrm{Hf}_{\max }$. The test was terminated when the blood lactate concentration of the exercising subject exceeded $4 \mathrm{mmol} \mathrm{l}^{-1}$ or by the subject's own request. Hf was recorded at 3 min 45 s (Polar Accurex, Kempele, Finland). Blood samples were withdrawn from the subject's thumb at the end of each exercise stage by pin prick and were analysed for whole blood lactate concentration using an Analox GM7 analyser (Analox Instruments, London, UK). Treadmill inclination was set at $0 \%$ throughout the assessment, and velocity was validated with an odometer (Trumeter, Radcliffe, UK).

\section{Lactate threshold determination}

Lactate threshold running velocity $\left(v-\mathrm{T}_{\mathrm{lac}}\right)$ was identified as the first significant elevation of blood lactate above resting levels. ${ }^{14}$ In order to achieve objectivity, a two phase linear regression model $^{15}$ was used in order to estimate the inflection point of the lactate profile "curve" (corresponding to the $v$ - $\mathrm{T}_{\text {lac }}$ ). A $\log$ transformation to both the running velocity and blood lactate concentration was applied in an attempt to gain a better estimate of the lactate threshold. ${ }^{16}$ Running velocity at a lactate concentration of $4 \mathrm{mmol} \mathrm{l}^{-1}(\mathrm{v}$ $4 \mathrm{mM}$ ) was calculated by linear extrapolation, using the lactate concentration points at the running velocities directly before and after attainment of $4 \mathrm{mmol} \mathrm{l}^{-1}$.

\section{Maximum heart frequency determination}

$\mathrm{Hf}_{\max }$ for the players were determined from the highest $\mathrm{Hf}$ recorded (Polar Accurex) from a $20 \mathrm{~m}$ multi-stage shuttle test ${ }^{17}$ completed before and after the pre-season training period.

\section{Training}

A diary of squad training throughout the full season was obtained. A typical training week consisted of four to seven

Table 2 Overview soccer season training of the professional youth players

\begin{tabular}{lllll}
\hline & \multicolumn{3}{l}{ Average hours training per week } \\
\cline { 2 - 5 } & $\begin{array}{l}\text { Pre-season- } \\
\text { Oct }\end{array}$ & Oct-Dec & Jan-Mar & Mar-Jun \\
\hline Warm up & 1.67 & 2.17 & 1.67 & 2.17 \\
Stretching & 1.5 & 1 & 1 & 1 \\
Endurance running & 3 & 1.5 & 1 & 0.5 \\
Small sided games & 2.5 & 1.75 & 2 & 1.25 \\
Technical training & 1 & 1.5 & 1.5 & 1 \\
Strength training & 1 & 1 & 1 & 0.5 \\
Match play & 1.5 & 1.5 & 2.25 & 3 \\
Total & 12.2 & 10.4 & 10.4 & 9.4 \\
\hline
\end{tabular}

training sessions and one/two soccer matches per week (table 2).

\section{Statistical analysis}

There were always some players unavailable at each testing time point, sometimes because of illness or international youth team commitments, but mostly because of injury. Therefore, considerable imbalance in the data in terms of missing values over the six testing time points occurred. Nine players had complete data and all results refer to this sub-set. A repeated measures ANOVA (with Greenhouse-Geisser corrections as necessary) was used to determine any significant changes in mean $v$ - $\mathrm{T}_{\text {lac }}$ and $v-4 \mathrm{mM}$ across the soccer season. Pearson's product-moment correlation was used to determine the relationships between variables. Data are expressed as means (SD).

\section{RESULTS}

Mean running velocity at $v-\mathrm{T}_{\text {lac }}$ and $v-4 \mathrm{mM}$ increased from the start of the pre-season training to October (fig 1 ), resulting in significantly lower lactate levels at each measured running velocity $(\mathrm{p}<0.001)$ (fig 2$)$. Mean running velocity at both lactate threshold markers increased from the start of pre-season training to October: $11.67(0.29)$ to 12.96 $(0.28) \mathrm{km} \mathrm{h}^{-1}$ for $v-\mathrm{T}_{\text {lac }}$ and $13.62(0.25)$ to $14.67(0.24)$ $\mathrm{km} \mathrm{h}^{-1}$ for $v-4 \mathrm{mM}(\mathrm{p}<0.001)$. There are no significant differences in lactate responses to increased running velocity at any of the other testing time points.

When lactate values are plotted against $\mathrm{Hf}$ at the running velocities tested from pre-season to October, that is, the period showing significant changes in lactate response, no significant differences in the lactate concentration to $\mathrm{Hf}$ relationship were found (fig 3 ). $\mathrm{Hf}_{\max }$ was unchanged across this time period, and subsequently $v-\mathrm{T}_{\text {lac }}$ and $v-4 \mathrm{mM}$ expressed as \% $\mathrm{Hf}_{\max }$ were unchanged.

The two different methods for determining lactate threshold were significantly correlated. Correlation between $v$ - $\mathrm{T}_{\text {lac }}$ and $v-4 \mathrm{mM}$ was $\mathrm{r}=0.87(\mathrm{p}<0.001)$. A significant correlation was also observed between Hf at $v-\mathrm{T}_{\text {lac }}$ and $v-4 \mathrm{mM}(\mathrm{r}=0.82$, $\mathrm{p}<0.001)$.

\section{DISCUSSION}

The main conclusion of this study is that aerobic endurance performance increased significantly from the start of the preseason training period to the early weeks of the competitive playing season (October), as evidenced by significant increases in mean running velocity at both $v$ - $\mathrm{T}_{\text {lac }}$ and $v$ $4 \mathrm{mM}$. This change is probably mainly attributable to the fact that the players returned to pre-season training in a detrained state, due to a summer intermission break of

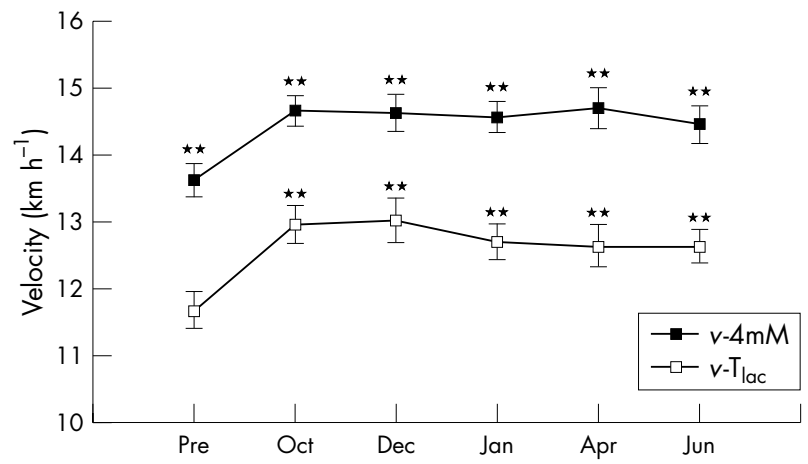

Figure 1 Running velocity at lactate thresholds $v-T_{\text {lac }}$ and $v-4 \mathrm{mM}$ at the six different time points using a flat treadmill. **Significantly different from pre-season $(p<0.001)$. 


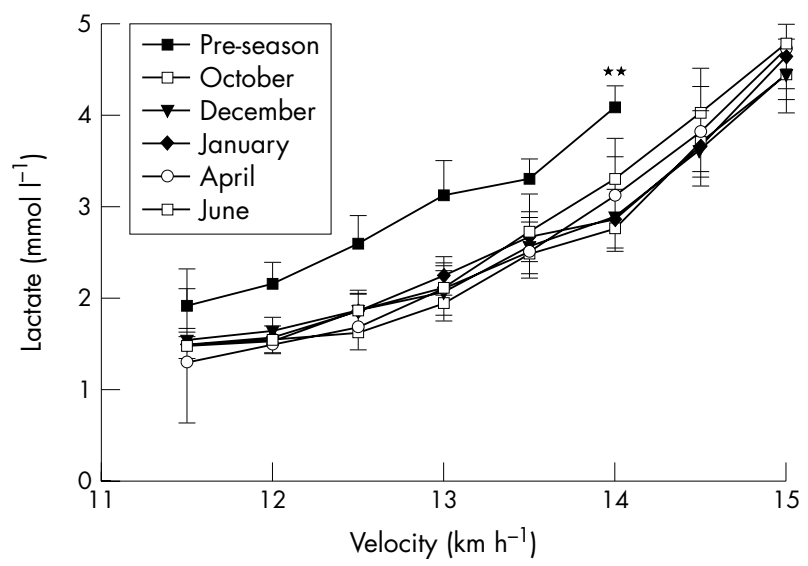

Figure 2 Lactate levels at fixed running velocities on a flat treadmill at different testing time points throughout the soccer season. ${ }^{*}$ Significantly different from all other time points $(p<0.001)$.

approximately 5 weeks duration. During the summer break the players were not involved in any structured aerobic fitness programme. Amigo et $a l^{18}$ investigated the effects of the summer intermission on amateur soccer players who had been training for 11 months prior to the summer break and found significant decrements in the cross-sectional area of slow twitch and fast twitch fibres, and a significant decrement in the activities of aerobic enzymes.

The finding of an improved aerobic endurance performance over the pre-season preparation period is supported by the studies of Bangsbo ${ }^{2}$ and Brady et al, ${ }^{12}$ although Dunbar ${ }^{11}$ reported no change in fixed blood lactate concentrations (FBLC) of 2 and $3 \mathrm{mmol} \mathrm{l}^{-1}$ over the pre-season period in a squad of English professional players. Bangsbo ${ }^{2}$ tested elite soccer players using sub-maximal blood lactate and $\mathrm{Vo}_{2 \max }$ assessment before and after a 5 week pre-season training period. At the end of the training period, $\mathrm{Vo}_{2 \max }$ was only slightly higher than before the pre-season, but blood lactate concentrations during sub-maximal running were significantly lower, resulting in a $25 \%$ higher mean running velocity at an FBLC of $3 \mathrm{mmol} \mathrm{l}^{-1}$, similar to the findings in the present study. Another study by Bangsbo ${ }^{2}$ involved quantifying aerobic fitness changes in a Danish soccer team over a 7 week in-season intermission period. Mean $\mathrm{Vo}_{2 \max }$ increased from 58.6 to $60.3 \mathrm{ml} \mathrm{kg}^{-1} \mathrm{~min}^{-1}$ across the preparation period and the mean blood lactate concentration during sub-maximal treadmill running ( 9 to $13 \mathrm{~km} \mathrm{~h}^{-1}$ ) was found to be significantly lower at all the treadmill velocities. The changes in blood lactate concentrations of approximately $1 \mathrm{mmol} \mathrm{l}^{-1}$ at the same running velocity were identical to the improvements in this study.

A change in lactate threshold can be expressed relative to $\mathrm{Vo}_{2 \max }$ or to $\mathrm{Hf}_{\text {max }}$. In this study, we have presented lactate values relative to $\mathrm{Hf}$ (fig 3 ), indicating that there is no significant change in relative lactate threshold from the start of pre-season training to the early days of the competitive season (October), although there are clearly higher running velocities at the same lactate values in October when compared to pre-season (fig 2). These findings are in line with those of Helgerud $e t \mathrm{al}^{3}$ who showed no change in lactate threshold (relative to $\mathrm{Hf}_{\max }$ and $\mathrm{Vo}_{2 \max }$ ) when significantly elevating $\mathrm{Vo}_{2 \max }$ after an endurance intervention period in soccer players. Although running velocity increased by $16 \%$ from 11 to $13.5 \mathrm{~km} \mathrm{~h}^{-1}(\mathrm{p}<0.05)$ in the study of Helgerud et $a_{1}{ }^{3}$ lactate threshold expressed relative to $\mathrm{Hf}_{\max }(87.4(2.3)$ to 87.6 (2.4) \% $\left.\mathrm{Hf}_{\max }\right)$ and $\mathrm{Vo}_{2 \max }(82.4$ (3.1) to 86.3 (2.1) $\left.\% \mathrm{Vo}_{2 \max }\right)$ was not significantly changed. It seems that lactate

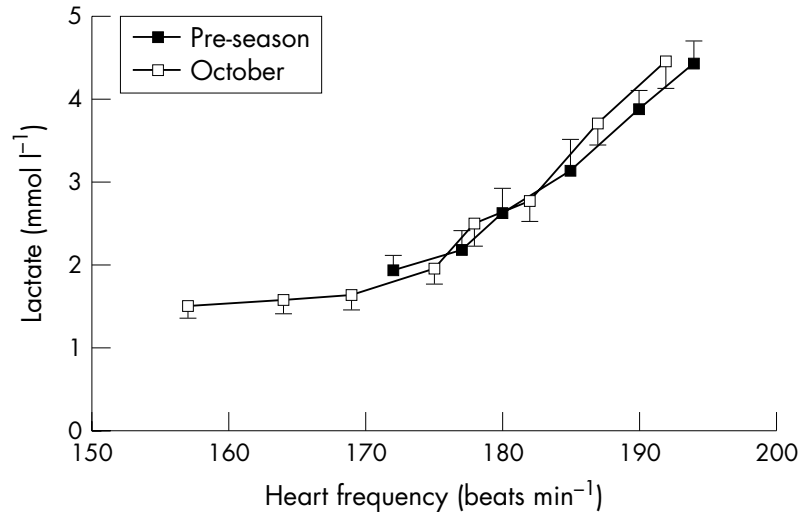

Figure 3 Lactate levels as a function of heart frequency before and after pre-season training.

threshold changes in tandem with $\mathrm{Vo}_{2 \max }$ in soccer players, and in terms of $\% \mathrm{Hf}_{\max }$ and $\% \mathrm{Vo}_{2 \max }$ the adaptability seems to be minor $(<5 \%) .^{3}{ }^{10} 19$

Reproducibility of the $v$ - $\mathrm{T}_{\text {lac }}$ and $v$-4mM using the same incremental treadmill protocol as in this study has been investigated recently $y^{20}$ with no differences in reproducibility found between $v$ - $\mathrm{T}_{\mathrm{lac}}$ and $v-4 \mathrm{mM}$. As can also be observed in fig 1 , any fixed lactate value between 2 and $4 \mathrm{mmol} \mathrm{l}^{-1}$ would reveal similar changes, and may be used for lactate assessment of soccer players.

Pate and Kriska ${ }^{21}$ have described a model that incorporates the three major factors accounting for inter-individual variance in aerobic endurance performance, namely $\mathrm{Vo}_{2 \max }$, lactate threshold, and work economy, with numerous published studies supporting this model. ${ }^{2223}$ Thus, the model serves as a useful framework for comprehensive examination of the effects of aerobic training on endurance performance. Since lactate threshold in relative terms does not change in this study, the explanation for improved aerobic performance may be attributable to changes in $\mathrm{Vo}_{2 \max }$ and/or running economy $\left(\mathrm{C}_{\mathrm{R}}\right)$.

$\mathrm{Vo}_{2 \max }$ has been suggested to be a very important factor for determining success in an aerobic endurance sport. ${ }^{24}{ }^{25}$ Previous studies have demonstrated a significant relationship between $\mathrm{Vo}_{2 \max }$ and distance covered during soccer match play $^{326}{ }^{27}$ and number of sprints attempted..$^{26}$ No correlation, however, has been documented between $\% \mathrm{Vo}_{2 \max }$ at lactate threshold and performance during soccer match play, although a significant correlation has been found between $v-4 \mathrm{mM}$ and distance covered by soccer referees $(\mathrm{r}=0.73$, $\mathrm{p}<0.05){ }^{28}$ An improved $\mathrm{Vo}_{2 \max }$ will lower the lactate concentration and $\mathrm{Hf}$ at a standardised running velocity, similar to what has been shown in this study. The improvements in running velocity at a standard lactate level and reduced $\mathrm{Hf}$ of approximately 10 beats $\min ^{-1}$ at a fixed speed after the pre-season preparation period may indicate an improved $\mathrm{VO}_{2 \max }$ in the range of $3-5 \mathrm{ml} \mathrm{kg}^{-1} \mathrm{~min}^{-1}$. ${ }^{9}$ Even though $\mathrm{Vo}_{2 \max }$ was not measured in this study, the most plausible explanation for the improvements may be related to an improved $\mathrm{Vo}_{2 \max }$.

Improvement in endurance performance in this study may also be attributed to improvements in $C_{R}$. Helgerud et $a l^{3}$ observed improvement in $C_{R}$ of soccer players when using a two-sessions-a-week specific running intervention. Hoff and Helgerud $^{329}$ have also demonstrated a $5 \%$ improvement in $C_{R}$ in soccer players when using a maximal strength training intervention. In the present study, however, no strength training in terms of heavy neuromuscular weight training was employed. $C_{R}$ was not measured in the present study, but it is plausible that $C_{R}$ may have changed across the season. 
This study has shown that aerobic endurance performance of professional youth soccer players increased significantly over the pre-season training period, but did not change significantly during the competitive season. The findings of the present study echo the findings of the historical study of Thomas and Reilly ${ }^{30}$ who reported that endurance fitness increased during the first third of the season and remained relatively stable throughout the course of the competitive season. The findings of the present study are in contrast to those of Brady et al ${ }^{12}$ who demonstrated deterioration of the player's endurance levels over the course of the competitive season following the achievement of peak fitness at the end of the pre-season training period. The authors suggested that the decrement of aerobic fitness levels towards the end of the season may have been a consequence of coaches "scaling down" training in order to save the players' efforts for competition. Time normally allocated for soccer training may be reduced as the soccer season progresses, due to an accumulation of competitive matches. A backlog of previously postponed matches and more matches in the latter stages of cup competitions for successful teams may decrease weekly time available for endurance training, especially in the last few months of the season. The endurance fitness gains manifested from the pre-season preparation period were successfully maintained for the remainder of the season in the present study. This may indicate that the physiological load of competing in two competitive soccer matches per week in conjunction with the training regime documented in the present study may be sufficient for maintaining endurance fitness levels during the in-season period. This means that it is important that soccer players who are not participating regularly in competitive matches perform additional individual endurance training to maintain, or even increase, their endurance levels. ${ }^{31}$ Soccer coaches are challenged to employ training strategies that increase the aerobic endurance performance of soccer players during the competitive in-season period, whilst not increasing the risk of over-reaching and over-training or promoting fatigue on match days that would adversely affect performance.

Although 37 players were available for testing throughout the season, only nine players were available for testing at all six testing time points. Three players left the squad during the study, and seven players were unavailable at one or more of the testing time points due to international commitments or illness. Therefore, most data collected in this study were excluded due to 18 players ( $49 \%$ of the squad) being injured at the time of one or more of the testing time points. Although this may seem a high occurrence of injury, studies by Hawkins et $a l^{32}$ and Woods et $a l^{33-35}$ have highlighted the high incidence of injury in professional soccer, especially in younger age groups. ${ }^{33}$

\section{Conclusions}

This study has shown that the endurance fitness of the soccer players increased over the pre-season to the early weeks of the competitive season, and was unchanged for the remainder of the season, in line with earlier findings. The results of this study also indicate that sub-maximal blood lactate assessment of soccer players can be used as an indicator of change in soccer players' endurance performance levels over a specified time period. This study has shown that any fixed blood lactate level between 2 and $4 \mathrm{mmol} \mathrm{l}^{-1}$ is appropriate during lactate assessment to determine sub-maximal responses to change in aerobic endurance levels. Since lactate threshold alterations appear to change in tandem with $\mathrm{Vo}_{2 \max }$ for soccer players, and also because $C_{R}$ of soccer players may be altered by specific endurance running and strength training interventions, it is suggested that $\mathrm{Vo}_{2 \max }$ and $\mathrm{C}_{\mathrm{R}}$ of professional soccer players should be primarily assessed.
What is already known on this topic

Aerobic endurance performance of soccer players has been shown to fluctuate across the soccer season. Sub-maximal lactate assessment has been previously used for monitoring changes in aerobic fitness levels of soccer players.

\section{What this study adds}

Fixed blood lactate levels between 2 and $4 \mathrm{mmol} \mathrm{I}^{-1}$ may be used as an indicator of aerobic endurance performance for soccer players. However, since lactate threshold does not change in relative terms after soccer training, other assessments such as $\mathrm{Vo}_{2 \max }$ and running economy may be more appropriate.

\section{Authors' affiliations}

K McMillan, R Macdonald, Medical Department, Glasgow Celtic FC, Glasgow, UK

J Helgerud, J Hoff, Faculty of Medicine, Norwegian University of Science and Technology, Trondheim, Norway

S J Grant, J Wilson, Institute of Biomedical and Life Sciences, West Medical Building, University of Glasgow, Glasgow, UK

J Newell, Mathematics Department, NUI Galway, Galway, Ireland

Competing interests: none declared

\section{REFERENCES}

1 Reilly T. Science and soccer. London: E and FN Spon, 1996.

2 Bangsbo J. The physiology of soccer - with special reference to intense intermittent exercise. Acta Physiol Scand 1994;619(Suppl):1-155.

3 Helgerud J, Engen LC, Wisloff $U$, et al. Aerobic endurance training improves soccer performance. Med Sci Sports Exerc 2001;33:1925-31.

4 Balsom PD. Evaluation of physical performance. In: Ekblom B, ed. Football (soccer). Oxford: Blackwell Scientific, 1994:102-23.

5 Weltman A. The blood lactate response to exercise, Current issues in exercise, monograph number 4. Champaign, IL: Human Kinetics, 1995.

6 Farrell PA, Wilmore JH, Coyle EF, et al. Plasma lactate accumulation and distance running performance. Med Sci Sports Exerc 1979;11:338-44.

7 Sjodin B, Jacobs I. Onset of blood lactate accumulation and marathon running performance. Int J Sports Med 1981;2:23-6.

8 Ramsbottom R, Williams C, Fleming N, et al. Training induced physiological and metabolic changes associated with improvements in running performance. Br J Sports Med 1989;23:171-6.

9 Helgerud J. Maximal oxygen uptake, anaerobic threshold and running economy in women and men with similar performances level in marathons. Eur J Appl Physiol Occup Physiol 1994;68:155-61.

10 Edwards AM, Clark N, Macfadyen AM. Lactate and ventilatory thresholds reflect the training status of professional soccer players where maximum aerobic power is unchanged. J Sports Sci Med 2003;2:23-9.

11 Dunbar J. Longitudinal change in aerobic capacity through the playing year in English professional soccer players. In: Fourth World Congress of Science and Football, Sydney, Congress Abstracts. Sydney: University of Technology, 1999.

12 Brady K, Maile A, Ewing B. An investigation into fitness levels of professional soccer players over two competitive seasons. J Sports Sci 1995;13:499.

13 Jensen K, Larsson B. Variations of physical capacity in a period including supplemental training of the Danish soccer team for women. In: Reilly T, Clarys J, Stibbe A, eds. Science and football II. London: E and FN Spon, 1993:114-7.

14 Kindermann W, Simon G, Keul J. The significance of the aerobic-anaerobic transition for the determination of work load intensities during endurance training. Eur J Appl Physiol Occup Physiol 1979;42:25-34.

15 Lundberg MA, Hughson RL, Weisiger KH, et al. Computerized estimation of lactate threshold. Comput Biomed Res 1986;19:481-6.

16 Beaver WL, Wasserman K, Whipp BJ. Improved detection of lactate threshold during exercise using a log-log transformation. J Appl Physiol 1985;59:1936-40.

17 Leger LA, Lambert J. A maximal multistage 20-m shuttle run test to predict VO2 max. Eur J Appl Physiol Occup Physiol 1982;49:1-12.

18 Amigo N, Cadefau JA, Ferrer l, et al. Effect of summer intermission on skeletal muscle of adolescent soccer players. I Sports Med Phys Fitness 1998;38:298-304

19 Hoff J, Helgerud J. Endurance and strength training for soccer players: physiological considerations. Sports Med 2004;34:165-80.

20 Grant S, McMillan K, Newell J, et al. Reproducibility of the blood lactate threshold, 4 mmol..$^{-1}$ marker, heart rate and ratings of perceived exertion during incremental treadmill exercise in humans. Eur J Appl Physiol 2002;87:159-66. 
21 Pate RR, Kriska A. Physiological basis of the sex difference in cardiorespiratory endurance. Sports Med 1984;1:87-98.

22 Di Prampero PE, Atchou G, Bruckner JC, et al. The energetics of endurance running. Eur J Appl Physiol Occup Physiol 1986;55:259-66.

23 Hoff J, Helgerud J, Wisløff U. Maximal strength training improves work economy in trained female cross-country skiers. Med Sci Sports Exerc 1999;31:870-7.

24 Åstrand P-O, Rodahl K. Textbook of work physiology. New York: McGrawHill, 1986

25 Saltin B. Maximal oxygen uptake: limitations and maleability. In: Nazar K, Terjung RL, eds. International perspectives in exercise physiology. Champaign, IL: Human Kinetics, 1990:26-40.

26 Smaros, G. Energy usage during a football match. In: Vecciet L, ed. Proceedings of the 1st International Congress on Sports Medicine Applied to Football. Rome: Guanillo D, 1980:795-801.

27 Bangsbo J. Physiological demands. In: Ekblom B, ed. Football (soccer). London: Blackwell Scientific, 1994:78-95.

28 Castagna C, Abt G, D'Ottavio S. The relationship between selected blood lactate thresholds and match performance in elite soccer referees. J Strength Cond Res 2002;16:623-7.
29 Hoff J, Helgerud, J. Maximal strength training enhances running economy and aerobic endurance performance. In: Hoff J, Helgerud J, eds. Football (soccer): new developments in physical training research. Trondheim: NTNU 2003:7-53.

30 Thomas V, Reilly T. Fitness assessment of English league soccer players through the competitive season. Br J Sports Med 1979;13:103-9.

31 Bangsbo J. Optimal preparation for the World Cup in soccer. Clin Sports Med 1998; 17:697-709.

32 Hawkins RD, Hulse MA, Wilkinson $C$, et al. The association football medical research programme: an audit of injuries in professional football. $\mathrm{Br} J$ Sports Med 2001;35:43-7.

33 Woods C, Hawkins R, Hulse M, et al. The Football Association Medical Research Programme: an audit of injuries in professional football - analysis of preseason injuries. Br J Sports Med 2002;36:436-41.

34 Woods C, Hawkins R, Hulse M, et al. The Football Association Medical Research Programme: an audit of injuries in professional football - an analysis of ankle sprains. Br J Sports Med 2003;37:233-8.

35 Woods C, Hawkins RD, Maltby S, et al. The Football Association Medical Research Programme: an audit of injuries in professional football - analysis of hamstring injuries. Br J Sports Med 2004;38:36-41.

\section{Clinical Evidence-Call for contributors}

Clinical Evidence is a regularly updated evidence-based journal available worldwide both as a paper version and on the internet. Clinical Evidence needs to recruit a number of new contributors. Contributors are healthcare professionals or epidemiologists with experience in evidence-based medicine and the ability to write in a concise and structured way.

Areas for which we are currently seeking authors:

- Child health: nocturnal enuresis

- Eye disorders: bacterial conjunctivitis

- Male health: prostate cancer (metastatic)

- Women's health: pre-menstrual syndrome; pyelonephritis in non-pregnant women

However, we are always looking for others, so do not let this list discourage you.

Being a contributor involves:

- Selecting from a validated, screened search (performed by in-house Information Specialists) epidemiologically sound studies for inclusion.

- Documenting your decisions about which studies to include on an inclusion and exclusion form, which we keep on file.

- Writing the text to a highly structured template (about 1500-3000 words), using evidence from the final studies chosen, within 8-10 weeks of receiving the literature search.

- Working with Clinical Evidence editors to ensure that the final text meets epidemiological and style standards.

- Updating the text every six months using any new, sound evidence that becomes available. The Clinical Evidence in-house team will conduct the searches for contributors; your task is simply to filter out high quality studies and incorporate them in the existing text.

- To expand the topic to include a new question about once every 12-18 months.

If you would like to become a contributor for Clinical Evidence or require more information about what this involves please send your contact details and a copy of your CV, clearly stating the clinical area you are interested in, to Klara Brunnhuber (kbrunnhuber@ bmigroup.com).

\section{Call for peer reviewers}

Clinical Evidence also needs to recruit a number of new peer reviewers specifically with an interest in the clinical areas stated above, and also others related to general practice. Peer reviewers are healthcare professionals or epidemiologists with experience in evidence-based medicine. As a peer reviewer you would be asked for your views on the clinical relevance, validity, and accessibility of specific topics within the journal, and their usefulness to the intended audience (international generalists and healthcare professionals, possibly with limited statistical knowledge). Topics are usually 1500-3000 words in length and we would ask you to review between 2-5 topics per year. The peer review process takes place throughout the year, and our turnaround time for each review is ideally 10-14 days.

If you are interested in becoming a peer reviewer for Clinical Evidence, please complete the peer review questionnaire at www.clinicalevidence.com or contact Klara Brunnhuber (kbrunnhuber@bmigroup.com). 